\title{
A COMPARATIVE STUDY OF ANTIMICROBIAL PROFILE HAVING BROAD SPECTRUM BACTERIOCINS AGAINST ANTIBIOTICS
}

\author{
SABIHA IMRAN ${ }^{1 *}$, TWINKLE GUPTA $^{1}$, AARTI ARORA $^{1}$, NILANJAN DAS $^{2}$ \\ ${ }^{1}$ Department of Biotechnology, Manav Rachna International University, Faridabad, Haryana, India. ${ }^{2}$ Accendere Knowledge Management \\ Services, Chennai, Tamil Nadu, India. Email: sabiha.fet @mriu.edu.in
}

Received: 28 April 2017, Revised and Accepted: 25 May 2017

\section{ABSTRACT}

Bacteriocins are ribosomally synthesized antimicrobial peptides produced by microbes owned by different eubacterial taxonomic branches. Most of them are small cationic membrane-active compounds that form pores in the targeted cells, disrupting membrane possibilities, and triggering cell fatality. The availability of small cationic peptides with antimicrobial activity is a protection strategy found not only in bacteria but also in plants and animals. The antibiotics which have extensive applications in the treatment of various bacterial diseases have developed alarming resistance against them in many pathogens due to improper use besides this antibiotics have adverse side effects also. There are an extensive variety of bacteriocins made by different bacterial genera have promising alternative to antibiotics that needs to be further studied to show the no existence of undesirable effects, which must be performed both in vitro and in vivo experimental systems. Most of the bacteriocin have narrow spectrum of their activity and effective only on the related species. There is an urgent need for the identification of broad-spectrum bacteriocins isolated from the species from different habitats that can be effective against both Gram-positive and Gram-negative pathogens. In this review, we focus on the main physical and chemical characteristics of broad-spectrum bacteriocin and discuss their application as an alternative option to antibiotics.

Keywords: Bacteriocins, Antibiotics, Broad spectrum, Narrow spectrum, Antimicrobial peptides.

(C) 2017 The Authors. Published by Innovare Academic Sciences Pvt Ltd. This is an open access article under the CC BY license (http://creativecommons. org/licenses/by/4. 0/) DOI: http://dx.doi.org/10.22159/ajpcr.2017.v10i9.19447

\section{INTRODUCTION}

Bacteriocins are peptides which are produced by both Gram-positive and Gram-negative bacteria [1]. They are synthesized by ribosomes showing antibacterial activity and are easily digested by enzymes such as trypsin and pepsin in human digestive system [2]. Mostly bacteriocins do not show any toxic effects and are heat stable [3]. Majority of the bacteriocins have a net positive charge which makes them fold into amphiphilic conformation when they interact with bacterial membranes.

Bacteriocins can be classified into three major classes on the basis of their structural and physiochemical properties [4]. Class I or lantibiotis are small peptides $(<5 \mathrm{KDa})$ which are heat stable and formed from two amino acid units of alanine by disulphide bonds or from an amino butyric acid linked to an amino acid alanine by a disulphide bond [5]. Nisin is a classical example of Class I bacteriocin [6]. Class II bacteriocins are nonlantibiotics which can be further divided into three subgroups. Class IIa peptides are active against Listeria such as pediocin PA-1 [7]. Class IIb consists of complex of two distinct proteins and have little activity such as lactococcin G. Class IIc are heat-stable peptides transported by leader peptides such as divergicine A. Class III bacteriocins are big peptides having more than 30KDa weight, for example helveticins J [8].

Activity of bacteriocins differs with respect to $\mathrm{pH}$. Various studies show that maximum activity occurs at $\mathrm{pH} 4$ and $\mathrm{pH} 5$ [9]. Acidic $\mathrm{pH}$ is favorable for production of bacteriocins by lactobacilli [10]. Bacteriocins can lose their activity due to enzymes such as proteinase $\mathrm{K}$ and pronase E. Bacteriocin has been reported from the bacterial species inhabiting in different environmental environment [11] and the maximum production of bacteriocin obtained by selecting the bestadapted culture media having appropriate sugar, vitamins, and nitrogen source [12]. It has been found that $\mathrm{NaCl}$ inhibits bacterial growth and bacteriocin production at higher concentration but shows no effect on the production of bacteriocins at concentration as low as 1\% [13]. Other factors such as temperature and incubation time also affect the bacteriocin production which varies strain wise.

\section{Applications of bacteriocins}

Bacterioncins have many beneficial roles including antibacterial, antimicrobial, antineoplastic, and probiotic activity, (Fig. 1) and thus, they are effective therapeutic agents [14]. There are some common bacteriocins such as pyocin, colicin, pediocin, and microcin which have inhibitory properties against different neoplastic cells [15]. There are immunotoxins and several bacterial proteins including Mycobacterium bovis MPT63, arginine deiminase from Mycoplasma arginini, lipidated azurin from Neisseria meningitidis, and azurin from Pseudomonas aeruginosa and Enterococcus mundtii strain C4110 which have already showed tremendous potential as anticancer bacteriocin [16].

Besides being an anticancer agent, bacteriocins are also used as food preservative. The food industry has led to search for the natural and chemical free products for food preservation as an increased demand by the consumers lactic acid bacteria are considered as generally recognized as safe (GRAS), which indicates their safe and easy application as food preservative that is why they are considered as a promising group of bacteriocins producing microorganisms. To know the target organism and the conditions in which the bacteriocins are active, a deeper characterization of bacteriocin is essential for their successful application in food preservatives [17]. Among alternative preservation technologies of the bacteriocin, some attention has been given to biopreservation to increase its shelf life and its hygienic conditions which minimize the nutritional properties [18].

\section{Antibiotics versus bacteriocins}

A significant invention in medical sciences is the discovery and advancement in the therapeutic applications of antibiotics. Antibiotics treat infections in patients having chronic diseases, receiving chemotherapy, or having surgeries such as organ transplants and cardiac surgery [24-26]. Moreover, antibiotics help to extend life expectancy by changing outcomes of bacterial infections [27]. In addition, antibiotics are also known to decrease morbidity and mortality rates [26]. They play an important role in achieving advances in surgery and saving patient's life [24]. Antibiotics can be either narrow spectrum, i.e. effective against specific families of bacteria or broad spectrum, i.e., effective against 
wide range of disease-causing bacteria. Bacteriocins also have many antibacterial properties just like antibiotics.

Use of antibiotics possesses many side effects such as malabsorption characterized by celiac like syndrome, no proper absorption of medications, altered metabolism and absorption of vitamins, colonization of resistant organisms, and changed susceptibility to infections. Another most common side effect of antibiotic intake is antibiotic-associated diarrhea causing frequent watery bowel movements [28].

With the growing use of antibiotics, another threat to health has come into effect, i.e., antibiotic resistance. Antimicrobial resistance is the failure of the therapy with a specific agent for an organism. Resistance is related to a trait inherent in microorganism which can be intrinsic or acquired. One of the largest factors which are leading to antibiotic resistance is indiscriminate and inappropriate use of antibiotics [29]. Hence, there is a need for some natural antibacterial peptides, such as bacteriocins, which can be used as an alternative to antibiotics.

There are few differences between bacteriocins and antibiotics in terms of the host cell immunity, mechanism of target cell resistance or tolerance, mode of action, toxicity and side effect mechanisms. Bacteriocins are antimicrobial peptides (AMPs) produced by bacteria which can also have either a broad or narrow spectrum of inhibition such as antibiotics (Table 2).

Most of the bacteriocins are considered as narrow spectrum which can only inhibit or kill the bacteria with close genetic relationship. The bacteriocins produced from Gram-positive bacteria are mostly broad spectra that show an inhibitory effect which is directed against bacteria of the same species as the bacteriocin producer and also against other species and genera different from that of the producer [35]. Very few bacteriocins are broad spectrum while bacteriocins with antibacterial action against multidrug-resistant strains are quite rare [36] (Table 1).

An example of broad host range bacteriocin is Lacticin 3147 which is produced by the GRAS organism Lactococcus lactis subsp. Lactis DPC3147 is a strain which is isolated from an Irish Kefir grain [37]. A number of broad host range bacteriocins which are termed as lantibiotics, a class of bacteriocins which is produced by Gram-positive bacteria, could be an interesting alternative to antibiotics to either prevent or treat bacterial infectious diseases which includes bovine mastitis, since these substances generally have a broad spectrum of activity against Gram-positive pathogens. The lantibiotics undergo substantial post- translational modifications, e.g., nisin, which is a 34 -amino acid peptide containing a number of modified amino acids which includes dehydrated residues and 5 cross-linking lanthionine or beta-methyl-lanthionine residues [38]

In this review paper, an emphasis has been given to highlight and discuss exclusively on the application of broad-spectrum bacteriocins as an alternative to classical antibiotics. The mechanisms of some broad-

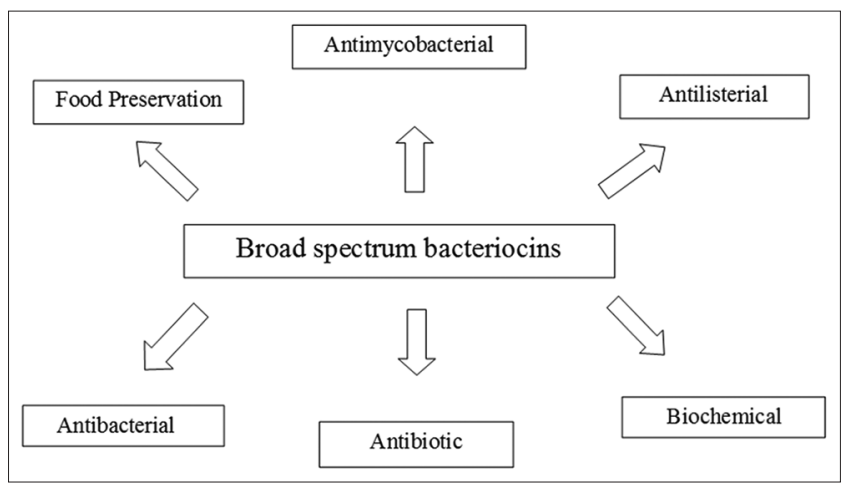

Fig. 1: Major activity profile of broad-spectrum bacteriocins spectrum bacteriocins and antibiotics have also been discussed and an attempt has been made to emphasize the effectiveness of bacteriocins as an effective alternative to the antibiotics having least harmful effects against the host organism in contrast to antibiotics.

\section{AMPs}

The search for novel AMPs involves the identification of active peptides from natural sources which are followed by the design of synthetic peptide analogs for structure-function studies. De novo peptide design approaches have also been used for various purposes such as structurebased modeling, predictive algorithms, and introduction of non-coded modifications to conventional peptide chemistry [39].

\section{Structure and charge distribution}

Generally, two physical features are common for AMPs: A cationic charge and a significant proportion of hydrophobic residues. The formerly property enhances selectivity for negatively charged microbial cytoplasmic membranes whereas the latter facilitates interactions with the fatty acyl chains [40]. There are also few anionic AMPs, such as dermcidin, although other biological activities seem to be more important for these peptides [41].

\section{LI-F type AMP}

Paenibacillus polymyxa strain JSa-9, a soil isolate that displays antibacterial and antifungal activities in vitro, has been found to produce LI-F type AMPs named AMP-JSa-9. LI-F type peptides are a group of broad-spectrum cyclic lipodepsipeptide antibiotic effective against Gram-positive bacteria and filamentous fungi. AMP-JSa-9 are a group of cyclic lipodesipeptide antibiotics which are composed of a peptide ring that consists of a six amino acid residues and a 15-guanidino-3hydroxypentadecanoic acid moiety and exhibit a broad antimicrobial spectrum with particularly high potency against Gram-positive bacteria and fungi $[42,43]$. Earlier studies suggested that the positively charged guanidinium group at the end of the 12-carbon lipidic tail and the presence of hydrophobic amino acids in the depsipeptide sequence of LI-Fs are important for the antibacterial activity [44]

\section{Mechanism of tigecycline}

Some antibiotics are broad spectrum such as tigecycline is a semisynthetic derivative of minocycline. It is mechanistically similar to aminoglycosides, macrolides, streptogramins, and oxazolidinones in that it binds to the 30 seconds ribosomal subunit [45]. This blocks the entry of aminoacyl tRNA to its acceptor site which prevents the bacterial protein synthesis and its growth. It overcomes two types of genetic mechanisms which are primarily responsible for clinical tetracycline resistance: Efflux and ribosomal protection [33,45]. However, it remains vulnerable to the multidrug efflux pumps of Proteeae and $P$. aeruginosa and less frequently, Bacteroides spp. through a different mechanism [46].

\section{Doripenem monohydrate}

Doripenem monohydrate is another broad-spectrum carbapenem antibiotic which derives its bactericidal action from inhibition of bacterial enzymes called penicillin-binding proteins (PBPs) [47-50]. These enzymes are responsible for synthesis of the bacterial cell wall, i.e., cross-linking of the peptidoglycan. The primary PBPs which are inhibited by the carbapenems are the high-molecular weight enzymes $1 \mathrm{a}, 1 \mathrm{~b}, 2$, and $3[50,51]$. The inhibition of PBP $1 \mathrm{a}$ and $1 \mathrm{~b}$ results in the formation of spheroplasts and rapid bacterial killing [52]. The inhibition

Table 1: Potent narrow- and broad-spectrum bacteriocins

\begin{tabular}{lll}
\hline Bacteriocins & $\begin{array}{l}\text { Narrow/broad } \\
\text { spectrum }\end{array}$ & Activities \\
\hline Cerein 7 [19] & Broad spectrum & Antibacterial \\
Bifidocin A [20] & Broad spectrum & Antibacterial \\
Lantibiotic lacticin 3147 [21] & Broad spectrum & Antimicrobial \\
Acidocin J1229 [22] & Narrow spectrum & Antimicrobial \\
Amylovorin L471 [23] & Narrow spectrum & Antibacterial \\
\hline
\end{tabular}


Table 2: Broad-spectrum bacteriocins and antibiotics with similar activities

\begin{tabular}{|c|c|c|c|}
\hline Activity & $\begin{array}{l}\text { Broad-spectrum } \\
\text { bacteriocins }\end{array}$ & $\begin{array}{l}\text { Antibiotics with similar } \\
\text { activity }\end{array}$ & Mode of action (bacteriocin and antibiotics) \\
\hline Antibacterial & AS-48 & 2-Naphthylcarbapenems & $\begin{array}{l}\text { AS-48 acts through permeation of the cell membrane leading to cell death [30] } \\
\text { 2-Naphthylcarbapenems: Appropriate positioning of cationic group has } \\
\text { been found to lead to enhanced activity against methicillin-resistant } \\
\text { Staphylococcus aureus and multiply resistant coagulase-negative staphylococci } \\
\text { while maintaining a good spectrum of Gram-negative activity [31] }\end{array}$ \\
\hline Antimicrobial & Lactocin XN8-A & Tigecycline & $\begin{array}{l}\text { Lactocin XN8-A: It induces membrane permeability and lead to pore formation } \\
\text { of target cells [32] } \\
\text { Tigecycline blocks access of aminoacyl tRNA to acceptor site, preventing protein } \\
\text { synthesis and growth [33] }\end{array}$ \\
\hline Antimicrobial & Bifidocin A & Doripenem monohydrate & $\begin{array}{l}\text { Bifidocin A causes leakage of } \mathrm{k}+\& \text { release of adenosine triphosphate causing } \\
\text { collapse of transmembrane electrical potential [20] } \\
\text { Doripenem Monohydrate: It inhibits the bacterial enzymes called PBPs which } \\
\text { inhibits cell wall synthesis [34] }\end{array}$ \\
\hline
\end{tabular}

of PBP 2 causes the rod-shaped organisms to become spherical and inhibition of PBP 3 results in the formation of filamentous-shaped organisms [53]. The PBP preferentially bound by doripenem which vary with the organism. In the case of Escherichia coli, doripenem preferentially binds to PBP 2 , followed by PBP $1 \mathrm{a}, 1 \mathrm{~b}$, and 3 . For P. aeruginosa, doripenem binds preferentially to PBP 2 and 3, followed by PBP $1 \mathrm{a}$ and $1 \mathrm{~b}$. With Streptococcus pneumonia, doripenem shows high affinity for PBP $1 a, 2 b$, and $2 x$

\section{Mode of action of bacteriocins}

Bacteriocins show different modes of action. In some cases, the target of action is the bacterial membrane. Other bacteriocins, however, inhibit essential enzymes within the cell such as leuconocin $\mathrm{S}$ or pediocin JD [54] and colicin E9 [55]. Some bacteriocins, such as nisin, show two common killing mechanisms sharing a common denominator [56-58]. It disrupts the integrity of cell membrane by forming pores leading to efflux of small metabolites due to dissipation of membrane potential, resulting in termination of biosynthetic processes and cell death. At lower concentrations, it binds with lipid II molecule of peptidoglycan layer resulting in prevention of proper cell wall synthesis, whereas at higher concentrations, this complex initiates membrane insertion creating pores in the bacterial cell wall. Hence, the nisin-lipid II complex facilitates the dual prevention mode of action involving cell wall synthesis and membrane pore formation [57]. Bacteriocin, such as cerein 7, is a peptidic antibiotic which is produced by Bacillus cereus Bc7 (CECT 5148) shows a broad spectrum of activity against Grampositive bacteria but is inactive against Gram-negative bacteria [59].

\section{Lacticin Q}

A unique killing mechanism of leaderless bacteriocins, such as lacticin $\mathrm{Q}$ has been well characterized [60]. It causes membrane permeabilization of strains without need of any specific receptors [61]. It forms a huge toroidal spore (HTP) causing leakage of intracellular components and large molecules which results in the cell death. HTP is formed due to electrostatic interaction of cationic lacticin Q molecule with negatively charged membranes, coupled with flip-flop. Another mechanism for selective antimicrobial activity of lacticin $Q$ is the accumulation of hydroxyl radicals through Fenton reaction, with variations within species and even within strains. The selective toxicity of lacticin $Q$ molecule depends on strains' ability to scavenge hydroxyl radicals [62].

These interactions can be either non-specific in the case of bacteriocins which show a broad activity spectrum (i.e., pediocin AcH/PA1 or nisin) or receptor-mediated in the case of species or strain-specific bacteriocins such as lactacin B. In some cases, there is an absolute need for the presence of the proton motive force which allows the successful interaction of the bacteriocin with the target membrane. In other cases, the interaction of the bacteriocin with the membrane is spontaneous. The result of this interaction is the generation of non-specific pores that allow an efflux of protons, ions, and amino acids but not cytoplasmic proteins. This efflux causes dissipation of the membrane potential and the collapse of the energy generation cellular machinery [63].

\section{CONCLUSION}

The effectiveness of bacteriocins as food preservatives is well demonstrated. Although nisin is the only purified bacteriocin used commercially, others are inhibitory against foodborne pathogens such as Listeria monocytogenes, their synthesis, and mode of action distinguish them from clinical antibiotics. Some of the mechanisms of broad-spectrum bacteriocins, such as lacticin, showed the effectiveness of bacteriocins against Gram-positive and Gram-negative bacteria. In addition, organisms that show resistance to antibiotics are generally not cross-resistant with bacteriocins, and unlike antibiotic resistance, bacteriocin resistance is not usually genetically determined. As the bacteriocin possesses much advantages over antibiotics could be considered as a potential safe alternative antimicrobial agent.

\section{ACKNOWLEDGMENT}

Authors sincerely acknowledge Accendere KMS research coordinators team for their support in drafting the manuscript.

\section{REFERENCES}

1. Tagg JR, Dajani AS, Wannamaker LW. Bacteriocins of gram-positive bacteria. Bacteriol Rev 1976;40(3):722.

2. Klaenhammer TR. Bacteriocins of lactic acid bacteria. Biochimie 1988;70(3):337-49.

3. Abriouel H, Valdivia E, Martí M, Maqueda M, Gálvez A. A simple method for semi-preparative-scale production and recovery of enterocin AS-48 derived from Enterococcus faecalis subsp. Liquefaciens A-4832. J Microbiol Methods 2003;55(3):599-605.

4. Zacharof MP, Lovitt RW. Bacteriocins produced by lactic acid bacteria a review article. APCBEE Procedia 2012;2(3):50-6.

5. Jarvis B, Jeffcoat J, Cheeseman GC. Molecular weight distribution of Nisin. Biochim Biophys Acta BBA Protein Struct 1968;168(1):153-5.

6. Broadbent JR, Chou YC, Gillies K, Kondo JK. Nisin inhibits several gram-positive, mastitis-causing pathogens. J Dairy Sci 1989;72(12):3342-5.

7. Venema K, Chikindas ML, Seegers JF, Haandrikman AJ, Leenhouts KJ, Venema G, et al. Rapid and efficient purification method for small, hydrophobic, cationic bacteriocins: Purification of lactococcin B and pediocin PA-1. Appl Environ Microbiol 1997;63(1):305-9.

8. Joerger MC, Klaenhammer TR. Characterization and purification of helveticin $\mathrm{J}$ and evidence for a chromosomally determined bacteriocin produced by Lactobacillus helveticus 481. J Bacteriol 1986;167(2):439-46.

9. Jack RW, Tagg JR, Ray B. Bacteriocins of gram-positive bacteria. Microbiol Rev 1995;59(2):171-200.

10. Balasubramanyam BV, Varadaraj MC. Cultural conditions for the production of bacteriocin by a native isolate of Lactobacillus delbruecki ssp. Bulgaricus CFR 2028 in milk medium. J Appl Microbiol 1998;84(1):97-102. 
11. Sanni AI, Onilude AA, Ogunbanwo ST, Smith SI. Antagonistic activity of bacteriocin produced by Lactobacillus species from ogi, an indigenous fermented food. J Basic Microbiol 1999;39(3):189-95.

12. Larsen AG, Vogensen FK, Josephsen J. Antimicrobial activity of lactic acid bacteria isolated from sour doughs: Purification and characterization of bavaricin A, a bacteriocin produced by Lactobacillus bavaricus MI401. J Appl Bacteriol 1993;75(2):113-22.

13. Sabiha I. Bacteriocin: An alternative to antibiotics. World J Pharm Res 2016;5(11):67-477.

14. Coley WB. II. Contribution to the knowledge of sarcoma. Ann Surg 1891;14(3):199-220

15. Felgner S, Kocijancic D, Frahm M, Weiss S. Bacteria in cancer therapy: Renaissance of an old concept. Int J Microbiol 2016;2016:8451728.

16. Yusuf MA, Ichwan SJ, Hamid TH. Anti-proliferative activities of purified bacteriocin from Enterococcus mundtii strain C4110 isolated from the caecum of Malaysian non-broiler chicken on cancer cell lines. Int J Pharm Pharm Sci 2015;7(2):334-7.

17. Bharti V, Mehta A, Singh S, Jain N, Ahirwal L, Mehta S. Bacteriocin: A novel approach for preservation of food. Int J Pharm Pharm Sci 2015;7(9):20-9.

18. Lewus CB, Montville TJ. Further characterization of bacteriocins plantaricin $\mathrm{BN}$, bavaricin $\mathrm{MN}$ and pediocin A. Food Biotechnol 1992;6(2):153-74

19. Abee T, Klaenhammer TR, Letellier L. Kinetic studies of the action of lactacin F, a bacteriocin produced by Lactobacillus johnsonii that forms poration complexes in the cytoplasmic membrane. Appl Environ Microbiol 1994;60(3):1006-13

20. Liu G, Song Z, Yang X, Gao Y, Wang C, Sun B. Antibacterial mechanism of bifidocin A, a novel broad-spectrum bacteriocin produced by Bifidobacterium animalis BB04. Food Control 2016;62:309-16.

21. McAuliffe O, Ryan MP, Ross RP, Hill C, Breeuwer P, Abee T. Lacticin 3147, a broad-spectrum bacteriocin which selectively dissipates the membrane potential. Appl Environ Microbiol 1998;64(2):439-45.

22. Tahara T, Oshimura M, Umezawa C, Kanatani K. Isolation, partial characterization, and mode of action of Acidocin J1132, a twocomponent bacteriocin produced by Lactobacillus acidophilus JCM 1132. Appl Environ Microbiol 1996;62(3):892-7.

23. Callewaert R, Holo H, Devreese B, Van Beeumen J, Nes I, De Vuyst L. Characterization and production of amylovorin L471, a bacteriocin purified from Lactobacillus amylovorus DCE 471 by a novel three-step method. Microbiology 1999;145(9):2559-68

24. Gould IM, Bal AM. New antibiotic agents in the pipeline and how they can help overcome microbial resistance. Virulence 2013;4(2):185-91.

25. Wright GD. Something old, something new: Revisiting natural products in antibiotic drug discovery 1. Can J Microbiol 2014;60(3):147-54.

26. Rossolini GM, Arena F, Pecile P, Pollini S. Update on the antibiotic resistance crisis. Curr Opin Pharmacol 2014;18(10):56-60.

27. Piddock LJ. The crisis of no new antibiotics-what is the way forward? Lancet Infect Dis 2012;12(3):249-53

28. Levy J. The effects of antibiotic use on gastrointestinal function. Am J Gastroenterol 2000;95 Suppl 1:S8-10.

29. Alanis AJ. Resistance to antibiotics: Are we in the post-antibiotic era? Arch Med Res 2005;36(6):697-705.

30. Jiménez-Díaz R, Rios-Sanchez RM, Desmazeaud M, Ruiz-Barba JL, Piard JC. Plantaricins S and T, two new bacteriocins produced by Lactobacillus plantarum LPCO10 isolated from a green olive fermentation. Appl Environ Microbiol 1993;59(5):1416-24.

31. Greenlee ML, DiNinno F, Herrmann JJ, Jaworsky C, Muthard DA, Salzmann TN. 2-naphthylcarbapenems: Broad spectrum antibiotics with enhanced potency against MRSA. Bioorg Med Chem Lett 1999;9(19):2893-6.

32. Chopra I. Glycylcyclines: Third-generation tetracycline antibiotics. Curr Opin Pharmacol 2001;1(5):464-9.

33. Zhanel GG, Homenuik K, Nichol K, Noreddin A, Vercaigne L, Embil J, et al. The glycylcyclines. Drugs 2004;64(1):63-88.

34. Matthews SJ, Lancaster JW. Doripenem monohydrate, a broadspectrum carbapenem antibiotic. Clin Ther 2009;31(1):42-63.

35. De Vuyst L, Leroy F. Bacteriocins from lactic acid bacteria: Production, purification, and food applications. J Mol Microbiol Biotechnol 2007;13(4):194-9.

36. Ryan MP, Rea MC, Hill C, Ross RP. An application in cheddar cheese manufacture for a strain of Lactococcus lactis producing a novel broad-spectrum bacteriocin, lacticin 3147. Appl Environ Microbiol 1996;62(2):612-9.

37. Cotter PD, Hill C, Ross RP. Bacteriocins: Developing innate immunity for food. Nat Rev Microbiol 2005;3(10):777-88.

38. Blondelle SE, Lohner K. Optimization and high-throughput screening of antimicrobial peptides. Curr Pharm Des 2010;16(28):3204-11.
39. Rotem S, Mor A. Antimicrobial peptide mimics for improved therapeutic properties. Biochim Biophys Acta BBA Biomembr 2009; 1788(8):1582-92.

40. Lohner K. Development of Novel Antimicrobial Agents: Emerging Strategies. Wymondham, UK: Horizon Scientific Press; 2001.

41. Harris F, Dennison SR, Phoenix DA. Anionic antimicrobial peptides from eukaryotic organisms. Curr Protein Pept Sci 2009;10(6):585-606.

42. Deng Y, Lu Z, Bi H, Lu F, Zhang C, Bie X. Isolation and characterization of peptide antibiotics LI-F04 and polymyxin B 6 produced by Paenibacillus polymyxa strain JSa-9. Peptides 2011;32(9):1917-23.

43. Deng Y, Lu Z, Lu F, Zhang C, Wang Y, Zhao H, et al. Identification of LI-F type antibiotics and di-n-butyl phthalate produced by Paenibacillus polymyxa. J Microbiol Methods 2011;85(3):175-82.

44. Bionda N, Pitteloud JP, Pitteloud JP, Cudic P. Solid-phase synthesis of fusaricidin/li-f class of cyclic lipopeptides: Guanidinylation of resinbound peptidyl amines. Pept Sci 2013;100(2):160-6.

45. Bush K, Macielag M. New approaches in the treatment of bacterial infections. Curr Opin Chem Biol 2000;4(4):433-9.

46. Livermore DM. Tigecycline: What is it, and where should it be used? J Antimicrob Chemother 2005;56(4):611-4.

47. Pharmaceutical OM. Doribax (Doripenem) Package Insert. Raritan, NJ: Ortho-McNeil Pharmaceutical; 2007.

48. Credito KL, Ednie LM, Appelbaum PC. Comparative antianaerobic activities of doripenem determined by MIC and time-kill analysis. Antimicrob Agents Chemother 2008;52(1):365-73.

49. Wagenlehner FM, Wagenlehner C, Weidner W, Naber KG. Urinary bactericidal activity of doripenem versus levofloxacin in patients with complicated urinary tract infections or pyelonephritis. Eur Urol Suppl 2008;7(3):268

50. Bonfiglio G, Russo G, Nicoletti G. Recent developments in carbapenems. Exp Opin Investig Drugs 2002;11(4):529-44

51. Sumita Y, Fakasawa M. Potent activity of meropenem against Escherichia coli arising from its simultaneous binding to penicillinbinding proteins 2 and 3. J Antimicrob Chemother 1995;36(1):53-64.

52. Curtis NA, Orr D, Ross GW, Boulton MG. Competition of betalactam antibiotics for the penicillin-binding proteins of $P$. aeruginosa, Enterobacter cloacae, Klebsiella aerogenes, Proteus rettgeri, and Escherichia coli: Comparison with antibacterial activity and effects upon bacterial morphology. Antimicrob Agents Chemother $1979 ; 16(3): 325-8$

53. Hayes MV, Orr DC. Mode of action of ceftazidime: Affinity for the penicillin-binding proteins of Escherichia coli K12, Pseudomonas aeruginosa and Staphylococcus aureus. J Antimicrob Chemother $1983 ; 12(2): 119-26$

54. Waite BL, Siragusa GR, Hutkins RW. Bacteriocin inhibition of two glucose transport systems in Listeria monocytogenes. J Appl Microbiol 1998;84(5):715-21.

55. PommerAJ, Wallis R, Moore GR, James R, Kleanthous C. Enzymological characterization of the nuclease domain from the bacterial toxin colicin E9 from Escherichia coli. Biochem J 1998;334(2):387-92.

56. Breukink E, Wiedemann I, van Kraaij C, Kuipers OP, Sahl HG, De Kruijff B. Use of the cell wall precursor lipid II by a pore-forming peptide antibiotic. Science 1999;286(5448):2361-4.

57. Wiedemann I, Breukink E, van Kraaij C, Kuipers OP, Bierbaum G, de Kruijff B, et al. Specific binding of Nisin to the peptidoglycan precursor lipid II combines pore formation and inhibition of cell wall biosynthesis for potent antibiotic activity. J Biol Chem 2001;276(3):1772-9.

58. Hsu ST, Breukink E, Tischenko E, Lutters MA, de Kruijff B, Kaptein R, et al. The Nisin-lipid II complex reveals a pyrophosphate cage that provides a blueprint for novel antibiotics. Nat Struct Mol Biol 2004;11(10):963-7.

59. Oscáriz JC, Lasa I, Pisabarro AG. Detection and characterization of cerein 7, a new bacteriocin produced by Bacillus cereus with a broad spectrum of activity. FEMS Microbiol Lett 1999;178(2):337-41.

60. Yoneyama F, Imura Y, Ichimasa S, Fujita K, Zendo T, Nakayama J, et al. Lacticin Q, a lactococcal bacteriocin, causes high-level membrane permeability in the absence of specific receptors. Appl Environ Microbiol 2009;75(2):538-41.

61. Yoneyama F, Imura Y, Ohno K, Zendo T, Nakayama J, Matsuzaki K, et al. Peptide-lipid huge toroidal pore, a new antimicrobial mechanism mediated by a lactococcal bacteriocin, lacticin Q. Antimicrob Agents Chemother 2009;53(8):3211-7.

62. Li M, Yoneyama F, Toshimitsu N, Zendo T, Nakayama J, Sonomoto K Lethal hydroxyl radical accumulation by a lactococcal bacteriocin, lacticin Q. Antimicrob Agents Chemother 2013;57(8):3897-902.

63. Sahl HG, Brandis H. Efflux of low-Mr substances from the cytoplasm of sensitive cells caused by the staphylococcin-like agent Pep 5. FEMS Microbiol Lett 1983;16(1):75-9. 